\title{
Diosmin Attenuates Methotrexate-Induced Hepatic, Renal, and Cardiac Injury: A Biochemical and Histopathological Study in Mice
}

\author{
Mohamed M. Abdel-Daim, ${ }^{1}$ Hesham A. Khalifa, ${ }^{2}$ Abdelrahman Ibrahim Abushouk, ${ }^{3}$ \\ Mohamed A. Dkhil, ${ }^{4,5}$ and Saleh A. Al-Quraishy ${ }^{4}$ \\ ${ }^{1}$ Pharmacology Department, Faculty of Veterinary Medicine, Suez Canal University, Ismailia, Egypt \\ ${ }^{2}$ Department of Pharmacology, Faculty of Veterinary Medicine, Zagazig University, Zagazig, Egypt \\ ${ }^{3}$ Faculty of Medicine, Ain Shams University, Cairo, Egypt \\ ${ }^{4}$ Department of Zoology, College of Science, King Saud University, Riyadh, Saudi Arabia \\ ${ }^{5}$ Department of Zoology and Entomology, College of Science, Helwan University, Cairo, Egypt
}

Correspondence should be addressed to Mohamed M. Abdel-Daim; abdeldaim.m@vet.suez.edu.eg

Received 22 March 2017; Revised 8 June 2017; Accepted 12 June 2017; Published 27 July 2017

Academic Editor: Francisco J. Romero

Copyright (c) 2017 Mohamed M. Abdel-Daim et al. This is an open access article distributed under the Creative Commons Attribution License, which permits unrestricted use, distribution, and reproduction in any medium, provided the original work is properly cited.

\begin{abstract}
The current study was designed to investigate the beneficial role of diosmin, a biologically active flavonoid, against methotrexate(MTX-) induced hepatic, renal, and cardiac injuries in mice. Male Swiss albino mice received a single intraperitoneal injection of MTX (at $20 \mathrm{mg} / \mathrm{kg}$, body weight) either alone or in combination with oral diosmin (at $50 \mathrm{or} 100 \mathrm{mg} / \mathrm{kg}$ body weight, for 10 days). Serum was used to evaluate tissue injury markers, while hepatic, renal, and cardiac tissue samples were obtained for determination of antioxidant activity as well as histopathological examination. Diosmin treatment ameliorated the MTXinduced elevation of serum alkaline phosphatase, aminotransferases, urea, creatinine, lactate dehydrogenase, and creatine kinases as well as plasma proinflammatory cytokines (interleukin-1-beta, interleukin-6, and tumor necrosis factor-alpha). Additionally, both diosmin doses significantly reduced tissue levels of malondialdehyde and nitric oxide and increased those of glutathione, glutathione peroxidase, glutathione reductase, glutathione S-transferase, superoxide dismutase, and catalase, compared to the MTX-intoxicated group. Histopathological examination showed that diosmin significantly minimized the MTX-induced histological alterations and nearly restored the normal architecture of hepatic, renal, and cardiac tissues. Based on these findings, diosmin may be a promising agent for protection against MTX-induced cytotoxicity in patients with cancer and autoimmune diseases.
\end{abstract}

\section{Introduction}

Methotrexate (MTX) is a widely known folate antimetabolite agent, used to treat several types of cancer [1] and autoimmune diseases [2]. Using MTX at cyclic high doses to treat malignant tumors can be associated with severe hepatotoxicity and acute renal failure [3, 4], while its chronic use at lower doses may cause progressive liver fibrosis, uremia, and hematuria $[4,5]$. Moreover, few articles have reported an acute toxic effect of MTX on the cardiovascular system [6]. Methotrexate-induced cytotoxicity can be a product of the interaction of several factors including the patient's risk factors, type of disease, dosing schedule, and treatment duration, as well as the presence of genetic apoptotic factors [7].

Long-term use of MTX leads to accumulation of its intracellular storage form "MTX polyglutamates," which has been suggested as a mechanism for MTX hepatotoxicity [8]. It also inhibits the cytosolic nicotinamide adenosine diphosphate- [NAD(P)-] dependent dehydrogenases, decreasing the cellular availability of NADP [9], which is normally used by glutathione reductase (GR) to maintain 


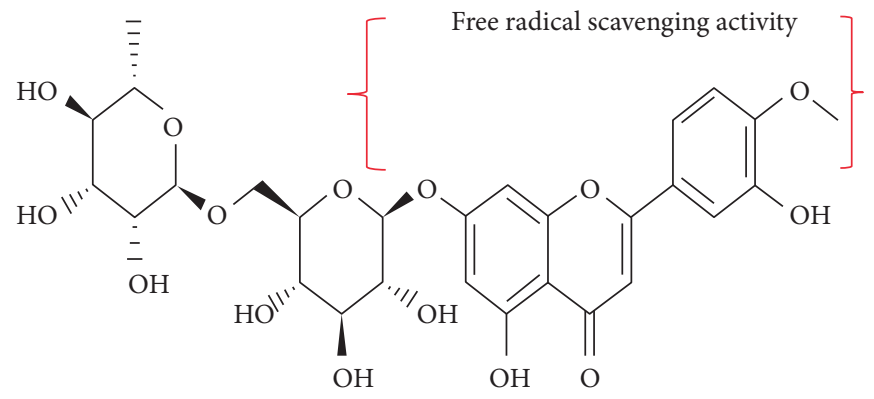

Figure 1: The chemical structure of diosmin. The area (in brackets) refers to the main antioxidant component of diosmin molecule.

the reduced state of glutathione (GSH) [10]. Moreover, its high affinity to dihydrofolate reductase inhibits the production of thymidylate, suppressing DNA synthesis [11]. Despite these side effects, MTX is a highly effective chemotherapeutic agent; therefore, research efforts should be directed at preventing and treating its cytotoxicity.

Diosmin (3',5,7-trihydroxy-4'-methoxyflavone 7-rutinoside) is an unsaturated flavonoid glycoside, present in citrus fruits (Figure 1) [12]. It is a biologically active polyphenol that has anti-inflammatory [13], antioxidant, antihyperglycemic [14], and antimutagenic properties [15]. In rat models, Ahmed and colleagues showed a nephroprotective role for diosmin against alloxan-induced nephropathy [16], while Tahir et al. highlighted its beneficial effect against alcoholic liver injury [13]. Moreover, diosmin could successfully improve cardiac function [17] and exert antihyperlipidemic effects against isopropanol-induced myocardial injury in rats [18].

A literature survey retrieved no scientific reports on the protective effects of diosmin against MTX toxicity. Therefore, in light of the above inferences from other evidence, we designed this study to investigate the beneficial role of diosmin against MTX-induced injuries to mouse hepatic, renal, and cardiac tissues.

\section{Materials and Methods}

2.1. Chemicals. Methotrexate was purchased from Shanxi PUDE Pharmaceutical Company (Shanxi, China), while diosmin was purchased from Sigma (St. Louis, MO, USA). All the assay kits were purchased from Biodiagnostics Co. (Cairo, Egypt), except for the kits of creatine kinase (CK) and CK-myoglobin binding (CK-MB) (Stanbio ${ }^{\mathrm{TM}}$, TX, USA), lactate dehydrogenase (LDH) enzymes (Randox Laboratories Ltd., UK), tumor necrosis factor- (TNF-) $\alpha$ (BioSource International Inc., Camarillo, CA, USA), interleukin- (IL-) $1 \beta$, and IL-6 (Glory Science Co. Ltd., Del Rio, TX, USA).

2.2. Mice. Thirty-two adult male Swiss albino mice, weighing 22 to $27 \mathrm{~g}$, were obtained from the Egyptian Organization for Biological Products and Vaccines. The animals were first acclimatized for seven days at the experiment site (animal house of the Department of Pharmacology, Faculty of Veterinary Medicine, Suez Canal University) under optimal environmental conditions (12-hour light-dark cycles, temperature $\left[20 \pm 2^{\circ} \mathrm{C}\right]$ with moderate humidity $\left.[60 \pm 5 \%]\right)$. All the animal handling procedures, used in this study, were approved by the Research Ethical Committee at the Faculty of Veterinary Medicine, Suez Canal University, Egypt (Approval number 201608).

2.3. Experimental Design. The mice were divided into four groups, each of eight. Mice in group I served as a negative control, receiving saline only during the entire experimental period. Mice in group II received a single intraperitoneal injection of MTX at a dose of $20 \mathrm{mg} / \mathrm{kg}$ bw (mimicking the acute exposure to an acute large dose in humans) [19]. Mice in groups III and IV received oral diosmin for 10 days at doses of 50 and $100 \mathrm{mg} / \mathrm{kg}$ bw [20], respectively. On the sixth day of the experiment, mice in groups III and IV received i.p MTX injection, at the same dose used in group II mice.

All animals were sacrificed on the 11th day after blood sample collection via direct cardiac puncture. The liver, heart, and kidneys were dissected into two parts: the 1st part was fixed with $10 \%$ formalin for further histopathological examination and the 2nd part was used for biochemical analysis. For the latter purpose, tissue pieces (each of $0.5 \mathrm{~g}$ ) were washed with cold normal saline and homogenized in 2.5 volumes of ice-cold 0.1 M potassium phosphate buffer ( $\mathrm{pH} 7.4$ ). The resulting homogenate underwent two cycles of centrifugation at $600 \mathrm{~g}$ and $10000 \mathrm{~g}$, and the supernatant was collected and stored at $-70^{\circ} \mathrm{C}$ to measure the tissue content of oxidative biomarkers and antioxidant enzymes.

2.4. Serum Biochemical Analysis. The obtained blood samples were allowed to clot for 30 minutes then centrifuged at $3000 \mathrm{rpm}$ for 15 minutes in order to obtain clear sera. The sera were then stored at $-20^{\circ} \mathrm{C}$ for further biochemical analysis. The methods described by Reitman and Frankel [21] to measure the serum levels of alanine transferase (ALT) and aspartate transferase (AST) and those described by Kind and King [22] to measure the serum level of alkaline phosphatase (ALP) were used. To estimate the serum levels of renal injury markers, we used the methods described by Larsen for measurement of serum creatinine [23] and those described by Coulombe and Favreau for measurement of serum urea [24]. In addition, the cardioprotective effect of diosmin was evaluated enzymatically by estimating the serum activity of CK and CK-MB, using Stanbio CK-NAC (UV-Rate)/CK-MB kits (TX, USA), according to the 
TABle 1: Ameliorative effects of diosmin on serum concentrations of hepatic, cardiac, and renal injury markers in mice exposed to methotrexate.

\begin{tabular}{|c|c|c|c|c|c|c|c|c|}
\hline Group & $\begin{array}{c}\text { AST } \\
(\mathrm{U} / \mathrm{ml}) \\
\end{array}$ & $\begin{array}{c}\text { ALT } \\
(\mathrm{U} / \mathrm{ml}) \\
\end{array}$ & $\begin{array}{l}\text { ALP } \\
(\mathrm{U} / \mathrm{l}) \\
\end{array}$ & $\begin{array}{l}\mathrm{LDH} \\
(\mathrm{U} / \mathrm{l})\end{array}$ & $\begin{array}{c}\mathrm{CK} \\
(\mathrm{U} / \mathrm{l}) \\
\end{array}$ & $\begin{array}{c}\text { CK-MB } \\
(\mathrm{U} / \mathrm{l})\end{array}$ & $\begin{array}{c}\text { Urea } \\
(\mathrm{mg} / \mathrm{dl})\end{array}$ & $\begin{array}{c}\text { Creatinine } \\
(\mathrm{mg} / \mathrm{dl})\end{array}$ \\
\hline Control & $30.7 \pm 1.8$ & $27.2 \pm 1.3$ & $68.3 \pm 1.6$ & $290.5 \pm 7.3$ & $116 \pm 3.1$ & $36.6 \pm 1.3$ & $22.3 \pm 1.5$ & $0.41 \pm 0.02$ \\
\hline MTX & $83 \pm 4.6^{*}$ & $71.5 \pm 2.7^{*}$ & $132.7 \pm 3.03^{*}$ & $440.7 \pm 10.3^{*}$ & $394 \pm 17.6^{*}$ & $190.3 \pm 15.6^{*}$ & $73.5 \pm 3.5^{*}$ & $2.1 \pm 0.15^{*}$ \\
\hline MTX-DM50 & $52 \pm 4.7^{* \#}$ & $42 \pm 2^{* \#}$ & $84.6 \pm 2.5^{* \#}$ & $347.2 \pm 15.7^{* \#}$ & $221 \pm 11.6^{* \#}$ & $89.4 \pm 4.3^{* \#}$ & $39 \pm 2.3^{* \#}$ & $1.2 \pm 0.13^{* *}$ \\
\hline MTX-DM100 & $36.9 \pm 2.8^{\#}$ & $30 \pm 1.4^{\#}$ & $71.2 \pm 2.6^{\#}$ & $307.6 \pm 9^{\#}$ & $146 \pm 9.7^{\#}$ & $45.7 \pm 4.3^{\#}$ & $26.4 \pm 2.4^{\#}$ & $0.57 \pm 0.04^{\#}$ \\
\hline
\end{tabular}

Values are means \pm SEM. ${ }^{*}$ Significant change at $p<0.01$ with respect to the negative control group. ${ }^{*}$ Significant change at $p<0.01$ with respect to the MTX group as the positive control group. ALP: alkaline phosphatase; ALT: alanine transferase; AST: aspartate transferase; CK: creatine kinase; LDH: lactate dehydrogenase.

methods described by Szasz et al. [25] and Würzburg et al. [26], respectively. Later, serum levels of LDH were measured according to Babson SR and Babson AL [27].

2.5. Evaluation of Tissue Lipid Peroxidation, Nitric Oxide, and Antioxidant Enzymes. For evaluation of lipid peroxidation, the methods described by Uchiyama and Mihara were used to measure the hepatic, cardiac, and renal tissue content of malondialdehyde (MDA) [28]. The concentration of nitric oxide (NO) in these tissues was assessed according to Green et al. [29]. Later, tissue levels of reduced GSH, superoxide dismutase (SOD), and catalase (CAT) were determined according to the methods described by Beutler et al. [30], Nishikimi et al. [31], and Aebi [32], respectively. Moreover, we measured tissue levels of glutathione S-transferase (GST), GR, and glutathione peroxidase (GPx) according to Habig et al. [33], Zanetti [34], and Paglia and Valentine [35], respectively.

2.6. Estimation of Proinflammatory Cytokines. Enzymelinked immunosorbent assay (ELISA) kits were used to measure the serum levels of TNF- $\alpha$ (BioSource International Inc., Camarillo, CA, USA), IL-1 $\beta$, and IL-6 (Glory Science Co. Ltd., Del Rio, TX, USA). The measurements were performed according to the manufacturer's instructions, and absorbance was read using an automated ELISA reader at $420 \mathrm{~nm}$.

2.7. Histopathological Examination. Using a rotatory microtome, $5 \mu \mathrm{m}$ thick sections were sliced from the liver, heart, and kidneys for histopathological examination. These sections were later stained with hematoxylin-eosin $(\mathrm{H} \& \mathrm{E})$ dye (Merck) and examined at 200x magnification using a power light microscope (Zeiss, Germany). We used a semiquantitative analysis to assess the tissue injury index in examined sections. The results were expressed as the sum of individual score grades (0: no findings, 1: mild, 2: moderate, or 3: severe) for each of the following parameters: degeneration, cellular swelling, cellular vacuolization, necrosis, congestion, and hemorrhage.

2.8. Statistical Analysis. We used SPSS (Statistical Package for Social Sciences) software (version 20) to perform the statisti$\mathrm{cal}$ analysis. All values were expressed as the mean and the standard error of mean (SEM). The means of different groups were compared using the one-way analysis of variance (ANOVA), followed by Tukey's post hoc comparison tests. A $p$ value $<0.05$ was considered statistically significant.

\section{Results}

\subsection{Biochemical Findings}

3.1.1. Serum Concentrations. Intraperitoneal injection of MTX significantly increased serum concentrations of AST, ALT, and ALP enzymes, compared to normal control levels $(p<0.01)$. However, treatment of MTX-injected mice with diosmin (at 50 and $100 \mathrm{mg} / \mathrm{kg} \mathrm{bw}$ ) significantly reduced the elevation of AST levels by $37.3 \%$ and $55.6 \%$, ALT levels by $41.3 \%$ and $58.1 \%$, and ALP levels by $36.2 \%$ and $46.4 \%$, respectively. Treatment of MTX-injected mice with $100 \mathrm{mg} /$ $\mathrm{kg}$ of diosmin restored serum concentrations of these parameters to normal control levels.

Similarly, MTX-injected mice showed a significant increase in serum concentrations of cardiac (CK and CKMB enzymes) as well as renal injury markers (urea and creatinine) in comparison to normal control mice $(p<0.01)$. Upon treatment of MTX-injected mice with diosmin (at 50 and $100 \mathrm{mg} / \mathrm{kg} \mathrm{bw}$ ), we recorded significant reductions in elevated serum levels of LDH by $21.2 \%$ and $30.2 \%$, CK by $44 \%$ and $63 \%$, CK-MB by $53 \%$ and $76 \%$, urea by $47.1 \%$ and $64.1 \%$, and creatinine by $42.2 \%$ and $73 \%$, respectively. As shown before, only the $100 \mathrm{mg} / \mathrm{kg}$ dose of diosmin could restore serum concentrations of these parameters to normal control levels (Table 1).

Plasma concentrations of inflammatory markers (IL$1 \beta$, IL-6, and TNF- $\alpha)$ were significantly higher $(p<0.01)$ in the MTX group than in the normal control group. Consistent with previous findings, diosmin treatment (at 50 and $100 \mathrm{mg} / \mathrm{kg} \mathrm{bw}$ ) significantly reduced plasma concentrations of IL- $1 \beta$ by $33.6 \%$ and $56.1 \%$, IL- 6 by $31.5 \%$ and $65.1 \%$, and TNF- $\alpha$ by $38 \%$ and $64.2 \%$, respectively. Interestingly, restoration of IL- $1 \beta$ and IL- 6 plasma concentrations in MTX-injected mice to normal control levels was noted only in the $100 \mathrm{mg} / \mathrm{kg}$ diosmin group; however, neither doses (50 and $100 \mathrm{mg} / \mathrm{kg} \mathrm{bw}$ ) could restore the plasma concentration of TNF- $\alpha$ in MTX-injected mice to normal levels (Figure 2).

3.1.2. Antioxidant Activity in Isolated Tissue Samples. Biochemical analysis of hepatic, cardiac, and renal tissues in MTX-injected mice showed a marked reduction in GSH concentration and antioxidant enzymes' levels (GST, GR, GPx, SOD, and CAT), as well as significant increases in MDA and NO tissue concentrations $(p<0.01)$. Administration 

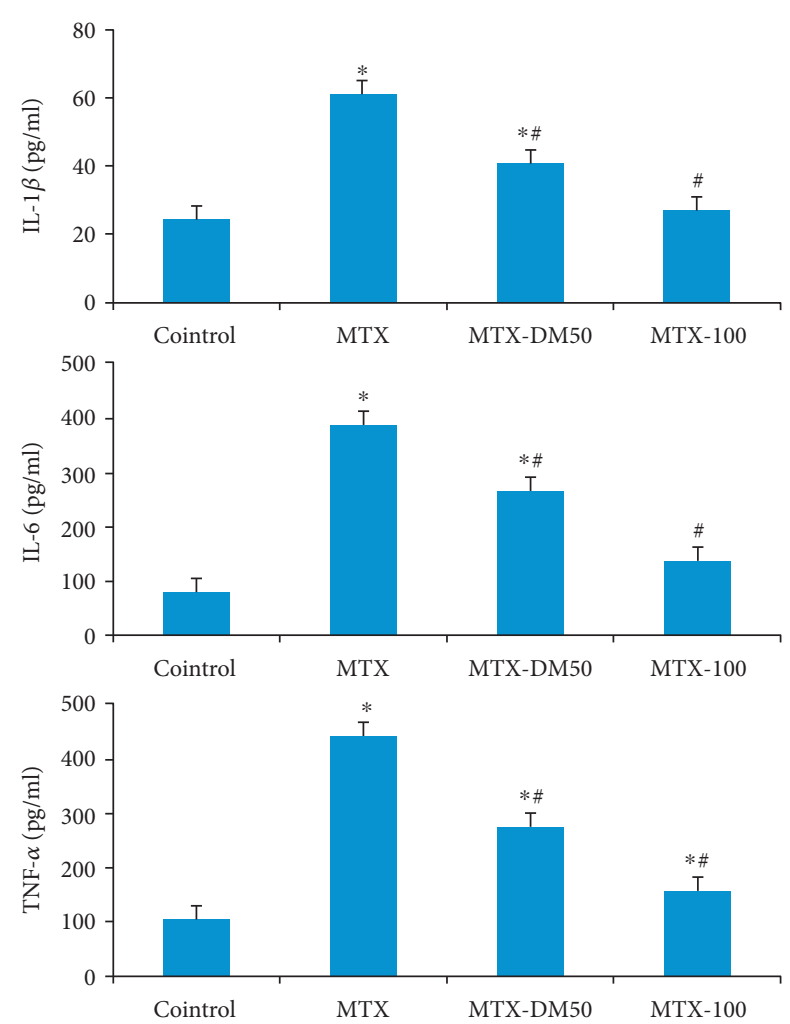

Figure 2: Effect of MTX with or without diosmin on proinflammatory cytokines IL- $1 \beta$, IL-6, and TNF- $\alpha$. DM: diosmin; IL: interleukin; MTX: methotrexate; TNF: tumor necrosis factor. ${ }^{*}$ Significant change at $p<0.01$ with respect to

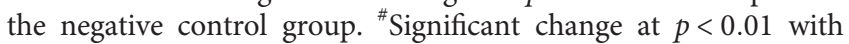
respect to the MTX group as the positive control group.

of diosmin significantly ameliorated the elevations of MDA and NO tissue concentrations in MTX-injected mice $(p<0.01)$. Moreover, it could increase tissue concentrations $(p<0.05)$ of GSH, as well as the activities of GST, GR, GPx, SOD, and CAT enzymes (Table 2).

\subsection{Histopathological Findings}

3.2.1. Liver. Liver tissue samples from the negative control group showed normal hepatic cells, arranged in cords around normal central veins. However, liver tissue samples from the MTX group showed focal areas of necrosis around the central vein, sinusoidal dilatation, vacuolar degeneration, and focal infiltration with leukocytes, mainly lymphocytes. In group III (MTX + diosmin $50 \mathrm{mg} / \mathrm{kg})$, moderate hepatocyte vacuolization, sinusoidal dilatation, and partial disruption of hepatic cords' arrangement were observed, while group IV (MTX + diosmin $100 \mathrm{mg} / \mathrm{kg}$ ) liver sections showed remarkable improvements of all MTX-induced histological changes (Figure 3).

3.2.2. Heart. Cardiac tissue microscopic slices from the negative control group showed normal histological appearance of cardiomyocytes with normal cigar-shaped nuclei. Conversely, we observed massive degenerative changes, cardiomyocyte necrosis, severe congestion, intermuscular edema, and intermuscular hemorrhage in mice that received MTX alone. In group III (MTX + diosmin $50 \mathrm{mg} / \mathrm{kg}$ ), we detected mild-to-moderate intermuscular hemorrhage and edema, while group IV (MTX + diosmin $100 \mathrm{mg} / \mathrm{kg}$ ) cardiac muscles showed minimal intermuscular edema with restoration of the normal cardiac tissue architecture (Figure 4).

3.2.3. Kidney. Microscopic examination of H\&E-stained renal tissue slices from the negative control group showed normal histological appearance with tubular arrangement of epithelial cells. On the contrary, tissue samples from the kidneys of group II mice (MTX) showed intensive degenerative changes and swelling of epithelial cells of the proximal tubules. Minimal areas of necrosis with pyknotic and karryorrhetic nuclei, as well as focal areas of severe vacuolar degeneration of proximal convoluted tubules, were also observed. In group III (MTX + diosmin $50 \mathrm{mg} / \mathrm{kg}$ ), we observed a moderate-to-severe swelling of tubular epithelial cells along with areas of mild vacuolar degeneration, while group IV (MTX + diosmin $100 \mathrm{mg} / \mathrm{kg}$ ) microscopic renal slices showed an improvement in tubular structure and minimal cellular swelling, compared to those of the MTX group (Figure 5).

Quantitative analysis showed that in comparison to the control group, MTX administration caused significantly higher tissue lesion scores $(p<0.01)$ in all examined organs. Interestingly, treatment with diosmin (both doses) caused a significant decrease in all tissue lesion scores, when compared to the MTX group (Table 3).

\section{Discussion}

This study highlights-for the first time-the protective role of diosmin against MTX-induced injuries to mouse hepatic, renal, and cardiac tissues. In experimental mice, diosmin was able to significantly reduce the biochemical and histological alterations, induced by MTX. These findings are mostly mediated via its antioxidant, anti-inflammatory, and antiapoptotic effects as shown by the decrease in oxidative and nitrative stress markers (MDA and NO), enhanced antioxidant defense mechanisms (GSH, SOD, and CAT), reduced serum levels of inflammatory cytokines (IL-1 $\beta$, IL-6, and TNF- $\alpha$ ), and the reduction in necrosis and vacuolar degeneration on histopathological examination after diosmin treatment.

The cytotoxic effects of MTX on the liver and kidneys were investigated in previous reports. Chladek et al. showed that MTX is metabolized in the liver by an enzymatic system [36]. The increased level of its cellular metabolites could induce oxidative and inflammatory tissue damages [37], which could be demonstrated in the form of histopathological changes [38] and elevation of serum liver enzymes [39]. Moreover, MTX metabolites were found to precipitate in renal tubules, causing marked nephrotoxicity in rats $[40,41]$.

Methotrexate can induce oxidative stress through inhibition of NADP synthesis, which is used by GR to maintain the reduced state of GSH. It can also induce nitrative stress by increasing the levels of TNF- $\alpha$ and IL- $1 \beta$, which increase 
TABLE 2: Ameliorative effects of diosmin on tissue concentrations of lipid peroxidation and antioxidant markers in mice exposed to methotrexate.

\begin{tabular}{|c|c|c|c|c|c|c|c|c|}
\hline Group & MDA (nmol/g) & $\mathrm{NO}(\mu \mathrm{mol} / \mathrm{g})$ & GSH (mg/g) & GST (U/g) & GR (U/g) & GPx (U/g) & SOD (U/g) & CAT (U/g) \\
\hline \multicolumn{9}{|c|}{ I. Hepatic tissue concentrations } \\
\hline Control & $28.9 \pm 1.8$ & $53.3 \pm 2.9$ & $0.41 \pm 0.02$ & $49.13 \pm 1.62$ & $43.95 \pm 1.45$ & $37.78 \pm 1.64$ & $116.4 \pm 3.99$ & $41.39 \pm 3.16$ \\
\hline MTX & $84.1 \pm 3.07^{*}$ & $104.8 \pm 2.9^{*}$ & $0.16 \pm 0.02 *$ & $19.84 \pm 1.74^{*}$ & $17.98 \pm 0.93^{*}$ & $15.92 \pm 1.75^{*}$ & $42.2 \pm 1.28^{*}$ & $19.9 \pm 2.24^{*}$ \\
\hline MTX-DM50 & $66.2 \pm 4.5^{* \#}$ & $83.3 \pm 2.5^{* \#}$ & $0.23 \pm 0.02^{*}$ & $32.26 \pm 2.08^{* \#}$ & $28.32 \pm 1.99^{* \#}$ & $24.38 \pm 1.94^{* \#}$ & $84.8 \pm 3.59^{* \#}$ & $30.07 \pm 2.52$ \\
\hline MTX-DM100 & $35.2 \pm 2.5^{\#}$ & $58.2 \pm 3.6^{\#}$ & $0.33 \pm 0.02^{\#}$ & $43.01 \pm 1.28^{\#}$ & $37.45 \pm 1.31^{* \#}$ & $28.70 \pm 3.92^{* \#}$ & $106.04 \pm 4.25^{\#}$ & $39.33 \pm 2.37^{\#}$ \\
\hline \multicolumn{9}{|c|}{ II. Cardiac tissue concentrations } \\
\hline Control & $49.47 \pm 2.7$ & $57.1 \pm 2.2$ & $26.8 \pm 1.0$ & $33.58 \pm 1.78$ & $5.76 \pm 0.34$ & $16.69 \pm 0.96$ & $57.32 \pm 2.3$ & $3.1 \pm 0.14$ \\
\hline MTX & $138.7 \pm 5.2^{*}$ & $158.7 \pm 5.5^{*}$ & $12.35 \pm 0.6^{*}$ & $16.65 \pm 0.57^{*}$ & $2.45 \pm 0.13^{*}$ & $7.20 \pm 0.29^{*}$ & $29.58 \pm 1.1^{*}$ & $0.73 \pm 0.05^{*}$ \\
\hline MTX-DM50 & $89.6 \pm 3.4^{* \#}$ & $97.5 \pm 3.4^{* \#}$ & $16.44 \pm 1.2^{*}$ & $24.42 \pm 0.92^{* \#}$ & $3.67 \pm 0.18^{* \#}$ & $10.62 \pm 0.62^{* \#}$ & $44.29 \pm 2.4^{* \#}$ & $1.3 \pm 0.08^{* \#}$ \\
\hline MTX-DM100 & $56.3 \pm 3.4^{\#}$ & $62.2 \pm 3.4^{\#}$ & $24.3 \pm 1.2^{\#}$ & $32.19 \pm 1.13^{\#}$ & $5.59 \pm 0.28^{\#}$ & $15.48 \pm 0.18^{\#}$ & $53 \pm 2.4^{\#}$ & $2.7 \pm 0.2^{\#}$ \\
\hline \multicolumn{9}{|c|}{ III. Renal tissue concentrations } \\
\hline Control & $36.8 \pm 2.42$ & $43.8 \pm 1.47$ & $9.04 \pm 0.12$ & $9.39 \pm 0.34$ & $13.06 \pm 0.48$ & $6.16 \pm 0.14$ & $57.2 \pm 1.24$ & $4.3 \pm 0.27$ \\
\hline MTX & $77.3 \pm 5.02^{*}$ & $87.6 \pm 3.6^{*}$ & $4.52 \pm 0.30^{*}$ & $5.23 \pm 0.27^{*}$ & $6.51 \pm 0.40^{*}$ & $2.96 \pm 0.19^{*}$ & $27.55 \pm 1.9^{*}$ & $2.05 \pm 0.31^{*}$ \\
\hline MTX-DM50 & $49.5 \pm 3.13^{\#}$ & $63.6 \pm 2.45^{* \#}$ & $6.04 \pm 0.43^{* \#}$ & $7.24 \pm 0.20^{* \#}$ & $9.30 \pm 0.28^{* \#}$ & $4.76 \pm 0.16^{* \#}$ & $43.9 \pm 3.9^{* \#}$ & $3.46 \pm 0.27^{\#}$ \\
\hline MTX-DM100 & $39.2 \pm 2.2^{\#}$ & $45.9 \pm 1.04^{\#}$ & $8.25 \pm 0.18^{\#}$ & $9.26 \pm 0.26^{\#}$ & $12.08 \pm 0.33^{\#}$ & $6.02 \pm 0.15^{\#}$ & $53.5 \pm 2.6^{\#}$ & $4.09 \pm 0.28^{\#}$ \\
\hline
\end{tabular}

Values are means \pm SEM. ${ }^{*}$ Significant change at $p<0.01$ with respect to the negative control group. ${ }^{*}$ Significant change at $p<0.01$ with respect to the MTX group as the positive control group. CAT: catalase; MDA: malondialdehyde; NO: nitric oxide; GPx: glutathione peroxidase; GR: glutathione reductase; GSH: glutathione; GST: glutathione S-transferase; SOD: superoxide dismutase.

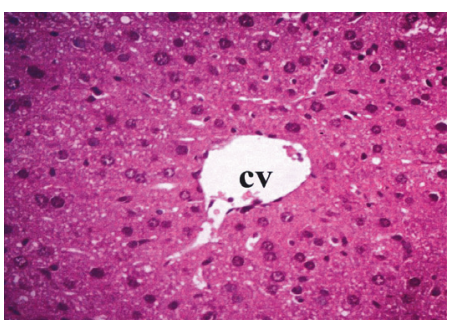

(a)

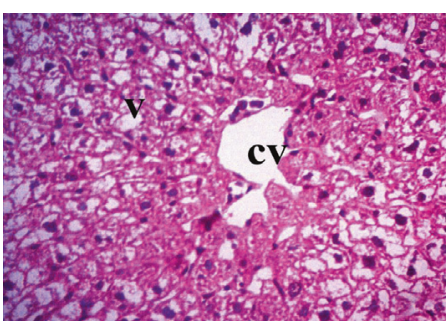

(c)

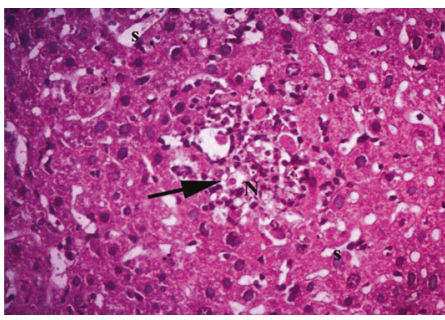

(b)

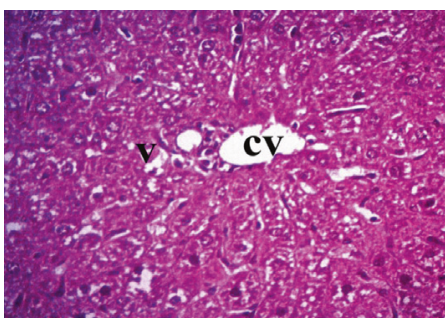

(d)

Figure 3: Histopathologic examination of liver tissue by H\&E at $\times 400$. CV: central vein; V: vacuolar degeneration; S: sinusoids. The arrow indicates necrosis and lymphocytic infiltrations. Groups are (a) normal liver tissue in the negative control group, (b) MTX group, (c) MTX + diosmin $50 \mathrm{mg} / \mathrm{kg}$ group, and (d) MTX + diosmin $100 \mathrm{mg} / \mathrm{kg}$ group.

the expression of inducible nitric oxide synthase (iNOS) and the production of NO and cyclic guanosine monophosphate (cGMP) [42]. Moreover, TNF- $\alpha$ can directly induce cytotoxicity to hepatocytes and glomerular and epithelial cells of the proximal convoluted tubules [43, 44]. In addition, IL- $1 \beta$ stimulates the synthesis of prostaglandin E2 in renal mesangial cells, changing the glomerular hemodynamics [45], while IL-6 increases the expression of fibronectin, causing thickening of the glomerular basement membrane [46].

Our study showed that diosmin mitigated MTX-induced oxidative and nitrative stresses by increasing GSH levels, lowering NO levels, and enhancing the activity of antioxidant enzymes. Tahir et al. showed that diosmin could alleviate ethanol-induced liver injury by reducing the activation of nuclear factor kappa B (NF- $\kappa \mathrm{B})$ and inhibiting the expression 


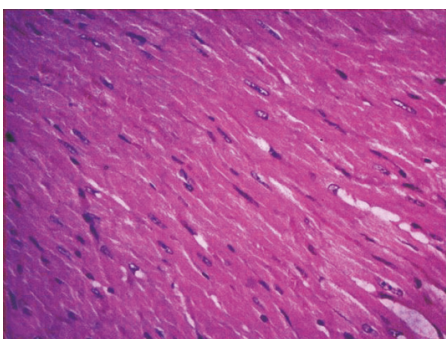

(a)

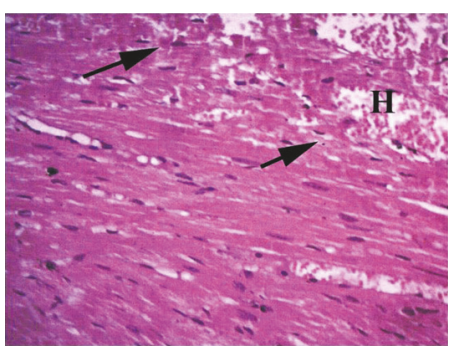

(c)

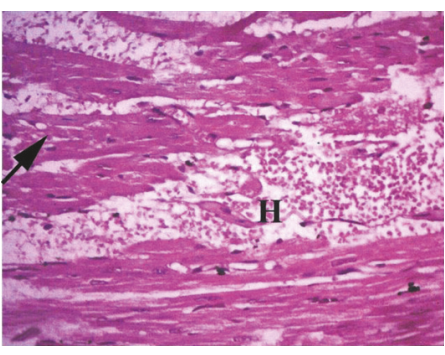

(b)

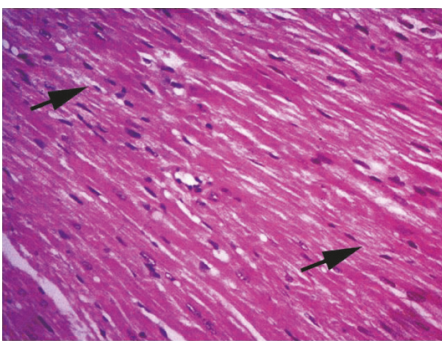

(d)

FIgURE 4: Histopathologic examination findings of cardiac tissue sections by $\mathrm{H} \& \mathrm{E}$ at $\times 400$. Arrows point to myocardiocyte degeneration.

$\mathrm{H}$ : hemorrhage. Groups are (a) control group showing normal myocardium, (b) MTX group, (c) MTX + diosmin $50 \mathrm{mg} / \mathrm{kg}$ group, and (d) MTX + diosmin $100 \mathrm{mg} / \mathrm{kg}$ group.

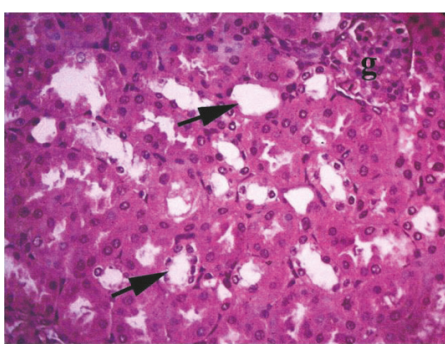

(a)

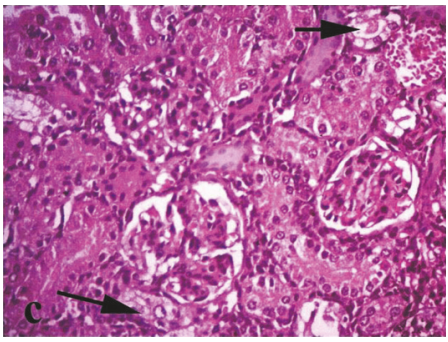

(c)

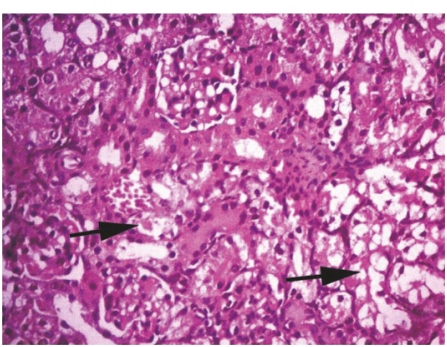

(b)

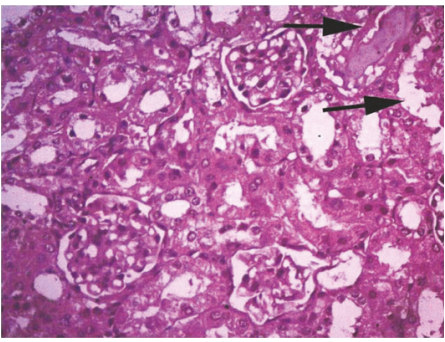

(d)

FIgURE 5: Histopathologic examination findings of kidney tissue by H\&E at $\times 400$. Arrows point to renal tubules. Groups are (a) control group showing normal renal tubules, (b) MTX group showing severe vacuolation, (c) MTX + diosmin $50 \mathrm{mg} / \mathrm{kg}$ group showing moderate degeneration, and (d) MTX + diosmin $100 \mathrm{mg} / \mathrm{kg}$ showing mild degeneration.

TABLE 3: Organ lesion scores in control and different experimental groups.

\begin{tabular}{lccrr}
\hline Lesion & & \multicolumn{2}{c}{ Experimental groups } \\
& Control & MTX & MTX-DM50 & $1.80 \pm 0.13^{* \#}$ \\
\hline Hepatic lesions & 0.00 & $3.00 \pm 0.00^{*}$ & $2.30 \pm 0.15^{* \#}$ & $1.20 \pm 0.13^{* \#}$ \\
Renal lesions & 0.00 & $3.00 \pm 0.00^{*}$ & $2.00 \pm 0.21^{* \#}$ & $1.90 \pm 0.31^{* \#}$ \\
Cardiac lesions & 0.00 & $3.00 \pm 0.00^{*}$ & $1.40 \pm 0.16^{* \#}$ \\
\hline
\end{tabular}

Data are expressed as means \pm SEM. * Significant change at $p<0.01$ with respect to the negative control group. ${ }^{*}$ Significant change at $p<0.01$ with respect to the MTX group as the positive control group. 
of TNF- $\alpha$, iNOS, and cyclooxygenase-II [13]. Rehman et al. used kidney injury molecule-1 (KIM-1), a highly sensitive biomarker for renal injury, to evaluate the protective role of diosmin against trichloroethylene (TCE) nephrotoxicity [47]. In agreement with other studies [48, 49], they reported that TCE administration increased the levels of renal KIM-1, while adding diosmin to TCE could effectively reduce these elevations.

To our knowledge, there is no study about the histological effects of MTX on the cardiac tissue. However, our data showed that MTX induces marked cardiac tissue damage in mice as indicated by the previously mentioned histopathological changes and elevation of plasma levels of cardiac enzymes (CK and CK-MB). These biochemical and histological changes were significantly reduced after diosmin treatment. In the same vein, previous reports showed the ability of diosmin to protect against isopropanol-induced myocardial infarction (at a daily dose of 5 to $10 \mathrm{mg} / \mathrm{kg} \mathrm{bw}$ ) and ischemia-/reperfusion-related cardiac dysfunction (at a daily dose of 50 to $100 \mathrm{mg} / \mathrm{kg} \mathrm{bw}$ ), as evidenced by restoration of normal echocardiographic patterns and reduction in plasma levels of cardiac troponins $[17,18]$. Diosmin can offer additional cardioprotection through its antihyperlipidemic (via inhibition of hepatic HMG CoA reductase), antihyperglycemic [14], and antihypertensive effects [50].

Histopathological analysis showed that MTX administration induced an acute inflammatory reaction, marked by vascular congestion, tissue edema, and infiltration by leukocytes. This reaction was explained in earlier studies by the ability of MTX to induce oxidative and nitrative stresses, as well as activation of nuclear factor $-\kappa \mathrm{B}(\mathrm{NF}-\kappa \mathrm{B})$ and $\mathrm{p} 38$ pathways $[19,51]$. Several degenerative changes were also noted, such as pyknotic and karryorrhetic nuclei, cellular vacuolization (reflecting dilatation of the smooth endoplasmic reticulum), and disturbance of tissue architecture.

The observed reduction in cellular necrosis and vacuolar degeneration following diosmin treatment may be related to (a) reduction in DNA damage indirectly through alleviation of MTX-induced oxidative stress and inflammation and (b) the possible antiapoptotic role of diosmin, demonstrated in previous experimental studies. For example, Liu et al. reported that diosmin protected against cerebral ischemia/ reperfusion injury in mice through activation of the JAK2/ STAT3 signaling pathway, a key regulator of cellular proliferation [52]. Moreover, Rehman et al. showed that diosmin offered nephroprotection in TCE-intoxicated mice by reducing the expression of Bax, p53, caspase-3, caspase-7, and caspase-9 [47].

Interestingly, several animal studies showed an antimutagenic effect of diosmin against esophageal [53], hepatic [54], colon [55], and buccal pouch tumors [56]. Rajasekar et al. concluded that diosmin (at a daily dose of $100 \mathrm{mg} / \mathrm{kg} \mathrm{bw}$ ) suppressed cellular proliferation and tumor progression in 7,12-dimethylbenz(a)anthracene- (DMBA-) induced hamster buccal pouch carcinoma through inhibition of the IL-6/ STAT3 signaling pathway [56]. Additionally, Tahir et al. and Tanaka et al. attributed the antimutagenic effect of diosmin to inhibition of cellular proliferation and downregulation of inflammatory markers [54, 55]. Therefore, adding diosmin to MTX does not only protect against its cytotoxicity but may also provide synergistic antimutagenic effects.

Based on our results, as well as those of previous reports, diosmin can exert its antioxidant effect directly (by free radical scavenging [57]) and indirectly (by upregulating cellular antioxidant enzymes, such as GR, GPx, CAT, and SOD). Earlier investigations have shown that several antioxidants, such as $\mathrm{N}$-acetylcysteine $[58,59]$, carvacrol $[60,61]$, curcumin [38, 62], and silymarin [63], can protect against MTXinduced hepatic and renal injury in animal models. Future studies should directly compare diosmin to these antioxidants to determine the optimal chemoprotective agent in this regard and whether diosmin has additional cytoprotective effects against MTX.

An earlier report by Iqbal and colleagues showed that MTX-induced nephrotoxicity can be ameliorated by folinic acid administration [64]; therefore, the effects of adding folinic acid as a supplement to diosmin should be investigated. Future studies should also test the protective role of diosmin against other chemotherapeutic agents. The antimutagenic and the cytoprotective effects of diosmin against chemotherapeutic drugs have been studied separately; therefore, further research should investigate the effects of diosmin on animal models with malignant tumors, receiving chemotherapeutic agents.

\section{Conclusion}

In experimental mice, diosmin significantly reduced the biochemical as well as the histological alterations, induced by MTX due to its antioxidant and anti-inflammatory activities. Therefore, diosmin may be a promising agent for protection against MTX-induced cytotoxicity in patients with cancer and autoimmune diseases. Future studies should investigate the effects of diosmin on animal models with malignant tumors and its potential for cytoprotection against other chemotherapeutic agents.

\section{Abbreviations}

ALP: $\quad$ Alkaline phosphatase

ALT: Alanine transferase

AST: Aspartate transferase

CK: $\quad$ Creatine kinase

CK-MB: Creatine kinase-myocardial B fraction

IL: $\quad$ Interleukin

LDH: Lactate dehydrogenase

MTX: Methotrexate

TNF: Tumor necrosis factor.

\section{Conflicts of Interest}

None was declared.

\section{Acknowledgments}

The authors would like to thank Professor Amina A. Dessouki, the professor of pathology, Faculty of Veterinary Medicine, Suez Canal University, for her help in the 
histopathological evaluations of this study. The authors would like to appreciate the Deanship of Scientific Research at King Saud University for funding this study through the research group project (no. RG-198).

\section{References}

[1] J. Jolivet, K. H. Cowan, G. A. Curt, N. J. Clendeninn, and B. A. Chabner, "The pharmacology and clinical use of methotrexate," New England Journal of Medicine, vol. 309, no. 18, pp. 1094-1104, 1983.

[2] J. A. M. Wessels, T. W. J. Huizinga, and H.-J. Guchelaar, "Recent insights in the pharmacological actions of methotrexate in the treatment of rheumatoid arthritis," Rheumatology, vol. 47, no. 3, pp. 249-255, 2008.

[3] E. M. Hersh, V. G. Wong, E. S. Henderson, and E. J. Freireich, "Hepatotoxic effects of methotrexate," Cancer, vol. 19, no. 4, pp. 600-606, 1966.

[4] P. E. Kintzel, "Anticancer drug-induced kidney disorders," Drug Safety, vol. 24, no. 1, pp. 19-38, 2001.

[5] H. Tobias and R. Auerbach, "Hepatotoxicity of long-term methotrexate therapy for psoriasis," Archives of Internal Medicine, vol. 132, no. 3, pp. 391-396, 1973.

[6] A. Perez-Verdia, F. Angulo, F. L. Hardwicke, and K. M. Nugent, "Acute cardiac toxicity associated with high-dose intravenous methotrexate therapy: case report and review of the literature," Pharmacotherapy: The Journal of Human Pharmacology and Drug Therapy, vol. 25, no. 9, pp. 1271-1276, 2005.

[7] M. G. Neuman, R. G. Cameron, J. A. Haber, G. G. Katz, I. M. Malkiewicz, and N. H. Shear, "Inducers of cytochrome P450 2E1 enhance methotrexate-induced hepatocytotoxicity," Clinical Biochemistry, vol. 32, no. 7, pp. 519-536, 1999.

[8] B. A. Kamen, P. A. Nylen, B. M. Camitta, and J. R. Bertino, "Methotrexate accumulation and folate depletion in cells as a possible mechanism of chronic toxicity to the drug," British Journal of Haematology, vol. 49, no. 3, pp. 355-360, 1981.

[9] W. H. Vogel, R. Snyder, and M. P. Schulman, "The inhibition of dehydrogenases by folic acid and several of its analogs," Biochemical and Biophysical Research Communications, vol. 10, pp. 97-101, 1963.

[10] K. Kurosawa, H. Shibata, N. Hayashi, N. Sato, T. Kamada, and K. Tagawa, "Kinetics of hydroperoxide degradation by NADP-glutathione system in mitochondria," The Journal of Biochemistry, vol. 108, no. 1, pp. 9-16, 1990.

[11] J. W. Williams, J. F. Morrison, and R. G. Duggleby, "Methotrexate, a high-affinity pseudosubstrate of dihydrofolate reductase," Biochemistry, vol. 18, no. 12, pp. 2567-2573, 1979.

[12] M. Szymański, D. Młynarek, A. Szymański, and I. Matławska, "Simultaneous determination of diosmin and hesperidin in pharmaceuticals by RPLC using ionic liquids as mobile phase modifiers," Iranian Journal of Pharmaceutical Research: IJPR, vol. 15, no. 1, p. 141, 2016.

[13] M. Tahir, M. U. Rehman, A. Lateef et al., "Diosmin protects against ethanol-induced hepatic injury via alleviation of inflammation and regulation of TNF- $\alpha$ and NF- $\kappa$ B activation," Alcohol, vol. 47, no. 2, pp. 131-139, 2013.

[14] S. Srinivasan and L. Pari, "Ameliorative effect of diosmin, a citrus flavonoid against streptozotocin-nicotinamide generated oxidative stress induced diabetic rats," Chemico-Biological Interactions, vol. 195, no. 1, pp. 43-51, 2012.
[15] T. Tanaka, H. Makita, M. Ohnishi et al., "Chemoprevention of 4-nitroquinoline 1-oxide-induced oral carcinogenesis in rats by flavonoids diosmin and hesperidin, each alone and in combination," Cancer Research, vol. 57, no. 2, pp. 246252, 1997.

[16] S. Ahmed, N. Mundhe, M. Borgohain et al., "Diosmin modulates the NF-kB signal transduction pathways and downregulation of various oxidative stress markers in alloxaninduced diabetic nephropathy," Inflammation, vol. 39, no. 5, pp. 1783-1797, 2016.

[17] O. Senthamizhselvan, J. Manivannan, T. Silambarasan, and B. Raja, "Diosmin pretreatment improves cardiac function and suppresses oxidative stress in rat heart after ischemia/ reperfusion," European Journal of Pharmacology, vol. 736, pp. 131-137, 2014.

[18] S. S. Queenthy and B. John, "Diosmin exhibits antihyperlipidemic effects in isoproterenol induced myocardial infarcted rats," European Journal of Pharmacology, vol. 718, no. 1-3, pp. 213-218, 2013.

[19] S. Mukherjee, S. Ghosh, S. Choudhury et al., "Pomegranate reverses methotrexate-induced oxidative stress and apoptosis in hepatocytes by modulating Nrf2-NF- $\kappa \mathrm{B}$ pathways," The Journal of Nutritional Biochemistry, vol. 24, no. 12, pp. 2040 2050, 2013.

[20] F. Imam, N. O. Al-Harbi, M. M. Al-Harbi et al., "Diosmin downregulates the expression of $\mathrm{T}$ cell receptors, proinflammatory cytokines and NF- $\kappa \mathrm{B}$ activation against LPSinduced acute lung injury in mice," Pharmacological Research, vol. 102, pp. 1-11, 2015.

[21] S. Reitman and S. Frankel, "A colorimetric method for the determination of serum glutamic oxalacetic and glutamic pyruvic transaminases," American Journal of Clinical Pathology, vol. 28, no. 1, pp. 56-63, 1957.

[22] P. R. N. Kind and E. J. King, "Estimation of plasma phosphatase by determination of hydrolysed phenol with amino-antipyrine," Journal of Clinical Pathology, vol. 7, no. 4, p. 322, 1954.

[23] K. Larsen, "Creatinine assay in the presence of protein with LKB 8600 reaction rate analyser," Clinica Chimica Acta, vol. 38, no. 2, pp. 475-476, 1972.

[24] J. J. Coulombe and L. Favreau, "A new simple semimicro method for colorimetric determination of urea," Clinical Chemistry, vol. 9, pp. 102-108, 1963.

[25] G. Szasz, J. Waldenström, and W. Gruber, "Creatine kinase in serum: 6. Inhibition by endogenous polyvalent cations, and effect of chelators on the activity and stability of some assay components," Clinical Chemistry, vol. 25, no. 3, pp. 446-452, 1979.

[26] U. Würzburg, N. Hennrich, H. Lang, W. Prellwitz, D. Neumeier, and M. Knedel, "Determination of creatine kinase-MB in serum using inhibiting antibodies (author's transl)," Klinische Wochenschrift, vol. 54, no. 8, pp. 357-360, 1976.

[27] S. R. Babson and A. L. Babson, "An improved amylase assay using dyed amylopectin," Clinica Chimica Acta, vol. 44, no. 2, pp. 193-197, 1973.

[28] M. Uchiyama and M. Mihara, "Determination of malonaldehyde precursor in tissues by thiobarbituric acid test," Analytical Biochemistry, vol. 86, no. 1, pp. 271-278, 1978.

[29] L. C. Green, D. A. Wagner, J. Glogowski, P. L. Skipper, J. S. Wishnok, and S. R. Tannenbaum, "Analysis of nitrate, nitrite, 
and $\left[{ }^{15} \mathrm{~N}\right]$ nitrate in biological fluids," Analytical Biochemistry, vol. 126, no. 1, pp. 131-138, 1982.

[30] E. Beutler, O. Duron, and B. M. Kelly, "Improved method for the determination of blood glutathione," The Journal of Laboratory and Clinical Medicine, vol. 61, pp. 882-888, 1963.

[31] M. Nishikimi, N. A. Rao, and K. Yagi, "The occurrence of superoxide anion in the reaction of reduced phenazine methosulfate and molecular oxygen," Biochemical and Biophysical Research Communications, vol. 46, no. 2, pp. 849-854, 1972.

[32] H. Aebi, "Catalase in vitro," Methods in Enzymology, vol. 105, pp. 121-126, 1984.

[33] W. H. Habig, M. J. Pabst, and W. B. Jakoby, "Glutathione S-transferases the first enzymatic step in mercapturic acid formation," Journal of Biological Chemistry, vol. 249, no. 22, pp. 7130-7139, 1974.

[34] G. Zanetti, "Rabbit liver glutathione reductase. Purification and properties," Archives of Biochemistry and Biophysics, vol. 198, no. 1, pp. 241-246, 1979.

[35] D. E. Paglia and W. N. Valentine, "Studies on the quantitative and qualitative characterization of erythrocyte glutathione peroxidase," The Journal of Laboratory and Clinical Medicine, vol. 70, no. 1, pp. 158-169, 1967.

[36] J. Chladek, J. Martinkova, and L. Sispera, “An in vitro study on methotrexate hydroxylation in rat and human liver," Physiological Research, vol. 46, no. 5, pp. 371-379, 1997.

[37] T. Çakır, A. Baştürk, C. Polat et al., "Does alfa lipoic acid prevent liver from methotrexate induced oxidative injury in rats?" Acta Cirurgica Brasileira, vol. 30, no. 4, pp. 247252, 2015.

[38] R. A. Hemeida and O. M. Mohafez, "Curcumin attenuates methotraxate-induced hepatic oxidative damage in rats," Journal of the Egyptian National Cancer Institute, vol. 20, no. 2, pp. 141-148, 2008.

[39] A. Aslaner, T. Çakır, B. Çelik et al., "The protective effect of intraperitoneal medical ozone preconditioning and treatment on hepatotoxicity induced by methotrexate," International Journal of Clinical and Experimental Medicine, vol. 8, no. 8, pp. 13303-13309, 2015.

[40] H. B. Ulusoy, İ. Öztürk, and M. F. Sönmez, "Protective effect of propolis on methotrexate-induced kidney injury in the rat," Renal Failure, vol. 38, no. 5, pp. 744-750, 2016.

[41] Y. Yuksel, R. Yuksel, M. Yagmurca et al., "Effects of quercetin on methotrexate-induced nephrotoxicity in rats," Human \& Experimental Toxicology, vol. 36, pp. 51-61, 2017.

[42] A. K. Kiemer, T. Hartung, and A. M. Vollmar, "cGMP-mediated inhibition of TNF- $\alpha$ production by the atrial natriuretic peptide in murine macrophages," The Journal of Immunology, vol. 165, no. 1, pp. 175-181, 2000.

[43] J. J. Navarro, F. F. Milena, C. Mora et al., "Tumor necrosis factor- $\alpha$ gene expression in diabetic nephropathy: relationship with urinary albumin excretion and effect of angiotensinconverting enzyme inhibition," Kidney International, vol. 68, pp. S98-S102, 2005.

[44] M. Jo, T.-H. Kim, D.-W. Seol et al., "Apoptosis induced in normal human hepatocytes by tumor necrosis factor-related apoptosis-inducing ligand," Nature Medicine, vol. 6, no. 5, pp. 564-567, 2000.

[45] M. B. Duran-Salgado and A. F. Rubio-Guerra, "Diabetic nephropathy and inflammation," World Journal of Diabetes, vol. 5, no. 3, pp. 393-398, 2014.
[46] J. F. Navarro-González and C. Mora-Fernández, "The role of inflammatory cytokines in diabetic nephropathy," Journal of the American Society of Nephrology, vol. 19, no. 3, pp. 433442, 2008 .

[47] M. U. Rehman, M. Tahir, A. Q. Khan et al., "Diosmin protects against trichloroethylene-induced renal injury in Wistar rats: plausible role of p53, Bax and caspases," British Journal of Nutrition, vol. 110, no. 4, pp. 699-710, 2013.

[48] Y. Zhou, V. S. Vaidya, R. P. Brown et al., "Comparison of kidney injury molecule- 1 and other nephrotoxicity biomarkers in urine and kidney following acute exposure to gentamicin, mercury, and chromium," Toxicological Sciences, vol. 101, no. 1, pp. 159-170, 2008.

[49] S. T. Ahmad, W. Arjumand, A. Seth et al., "Preclinical renal cancer chemopreventive efficacy of geraniol by modulation of multiple molecular pathways," Toxicology, vol. 290, no. 1, pp. 69-81, 2011.

[50] T. Silambarasan and B. Raja, "Diosmin, a bioflavonoid reverses alterations in blood pressure, nitric oxide, lipid peroxides and antioxidant status in DOCA-salt induced hypertensive rats," European Journal of Pharmacology, vol. 679, no. 1-3, pp. 8189, 2012.

[51] Y.-J. Kim, M. Song, and J.-C. Ryu, "Inflammation in methotrexate-induced pulmonary toxicity occurs via the p38 MAPK pathway," Toxicology, vol. 256, no. 3, pp. 183190, 2009.

[52] X. Liu, X. Zhang, J. Zhang et al., "Diosmin protects against cerebral ischemia/reperfusion injury through activating JAK2/STAT3 signal pathway in mice," Neuroscience, vol. 268, pp. 318-327, 2014.

[53] T. Tanaka, H. Makita, K. Kawabata et al., "Modulation of Nmethyl-N-amylnitrosamine-induced rat oesophageal tumourigenesis by dietary feeding of diosmin and hesperidin, both alone and in combination," Carcinogenesis, vol. 18, no. 4, pp. 761-769, 1997.

[54] M. Tahir, M. U. Rehman, A. Lateef et al., "Diosmin abrogates chemically induced hepatocarcinogenesis via alleviation of oxidative stress, hyperproliferative and inflammatory markers in murine model," Toxicology Letters, vol. 220, no. 3, pp. 205218, 2013.

[55] T. Tanaka, H. Makita, K. Kawabata et al., "Chemoprevention of azoxymethane-induced rat colon carcinogenesis by the naturally occurring flavonoids, diosmin and hesperidin," Carcinogenesis, vol. 18, no. 5, pp. 957-965, 1997.

[56] M. Rajasekar, K. Suresh, and K. Sivakumar, "Diosmin induce apoptosis through modulation of STAT-3 signaling in 7,12 dimethylbenz(a)anthracene induced harmster buccal pouch carcinogenesis," Biomedicine \& Pharmacotherapy, vol. 83, pp. 1064-1070, 2016.

[57] H. H. Arab, S. A. Salama, H. A. Omar, E. S. Arafa, and I. A. Maghrabi, "Diosmin protects against ethanol-induced gastric injury in rats: novel anti-ulcer actions," PloS One, vol. 10, no. 3, article e0122417, 2015.

[58] A. Cetinkaya, E. Bulbuloglu, E. B. Kurutas, and B. Kantarceken, "N-acetylcysteine ameliorates methotrexate-induced oxidative liver damage in rats," Medical Science Monitor, vol. 12, no. 8, pp. BR274-BR278, 2006.

[59] Y. Cağlar, H. Özgür, I. Matur et al., "Ultrastructural evaluation of the effect of $\mathrm{N}$-acetylcysteine on methotrexate nephrotoxicity in rats," Histology and Histopathology, vol. 28, no. 7, pp. 865-874, 2013. 
[60] M. Bozkurt, M. N. Bodakci, G. Turkcu et al., "Protective effects of carvacrol against methotrexate-induced liver toxicity in rats," Acta Chirurgica Belgica, vol. 114, no. 6, pp. 404-409, 2014.

[61] M. Bozkurt, S. Em, P. Oktayoglu et al., "Carvacrol prevents methotrexate-induced renal oxidative injury and renal damage in rats," Clinical \& Investigative Medicine, vol. 37, pp. 19-25, 2014.

[62] M. A. Morsy, S. A. Ibrahim, E. F. Amin, M. Y. Kamel, R. A. Rifaai, and M. K. Hassan, "Curcumin ameliorates methotrexate-induced nephrotoxicity in rats," Advances in Pharmacological Sciences, vol. 2013, Article ID 387071, 7 pages, 2013.

[63] D. O. Dabak and N. Kocaman, "Effects of silymarin on methotrexate-induced nephrotoxicity in rats," Renal Failure, vol. 37, no. 4, pp. 734-739, 2015.

[64] M. Perwaiz Iqbal, F. Sultana, N. Mehboobali, and S. Pervez, "Folinic acid protects against suppression of growth by methotrexate in mice," Biopharmaceutics \& Drug Disposition, vol. 22, no. 4, pp. 169-178, 2001. 


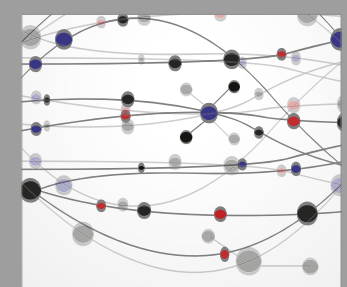

The Scientific World Journal
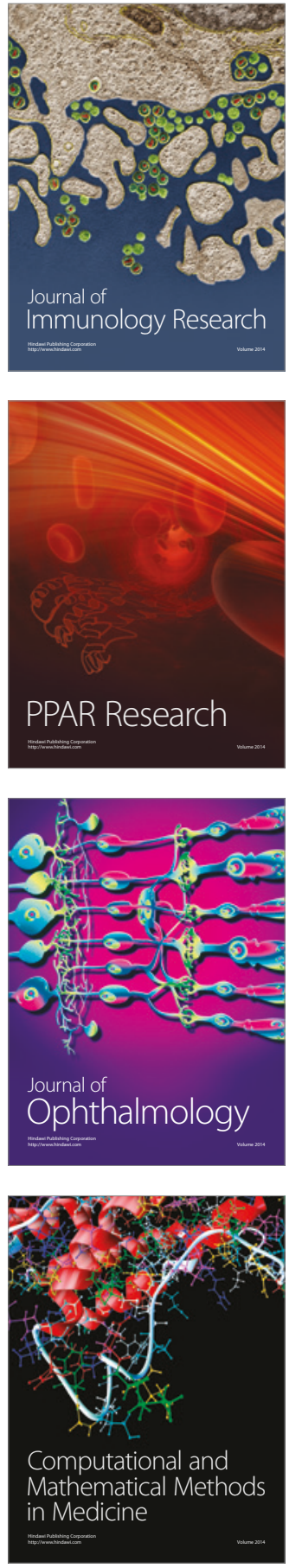

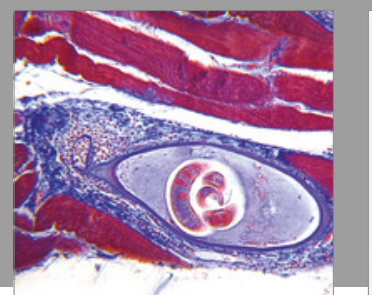

Gastroenterology Research and Practice
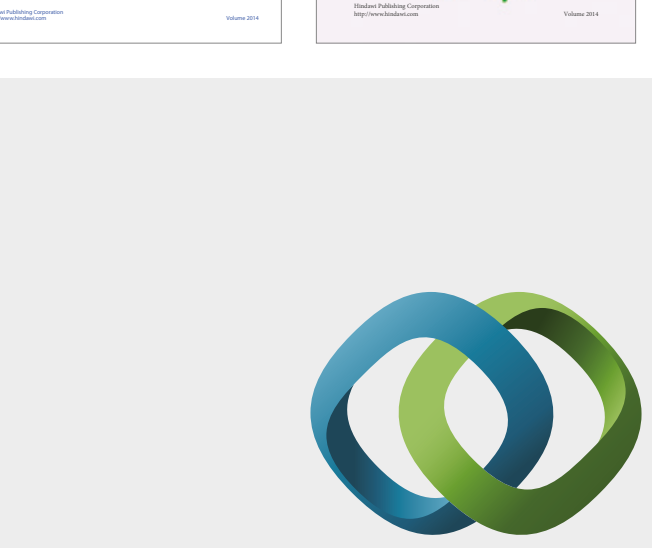

\section{Hindawi}

Submit your manuscripts at

https://www.hindawi.com
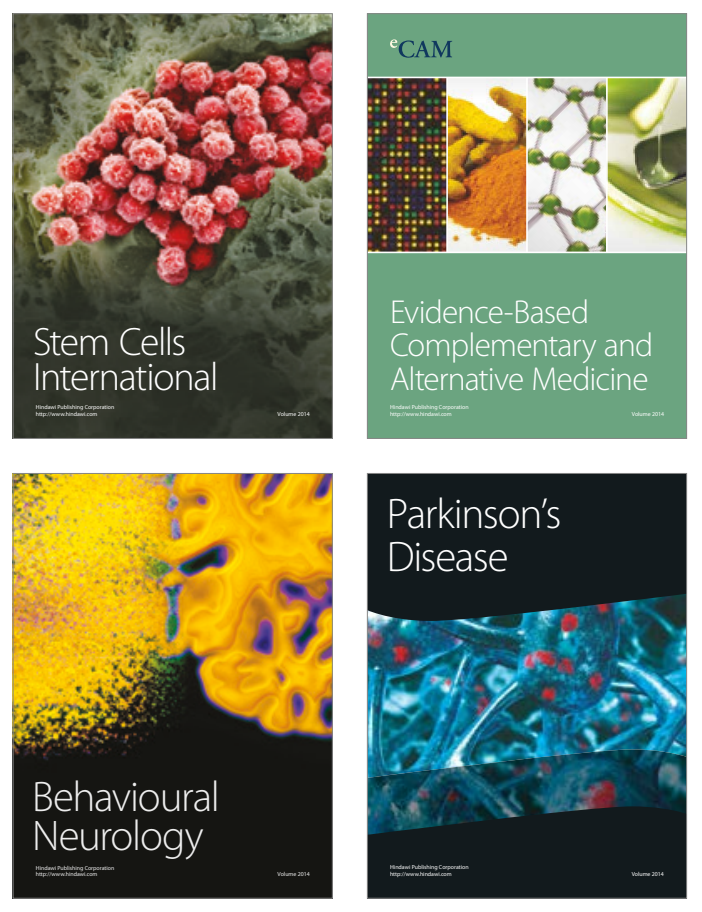
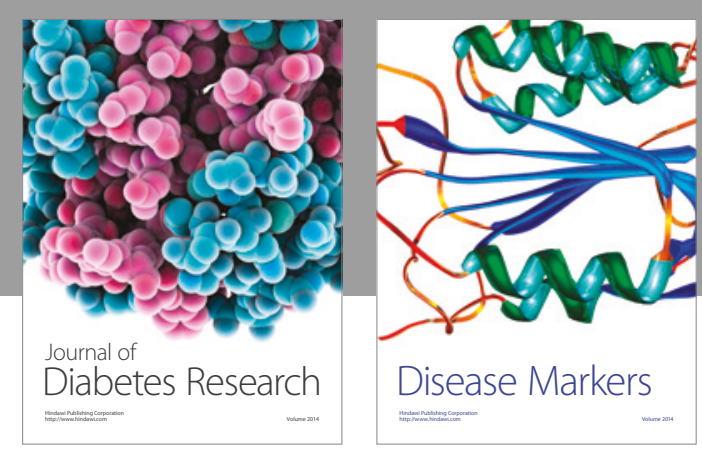

Disease Markers
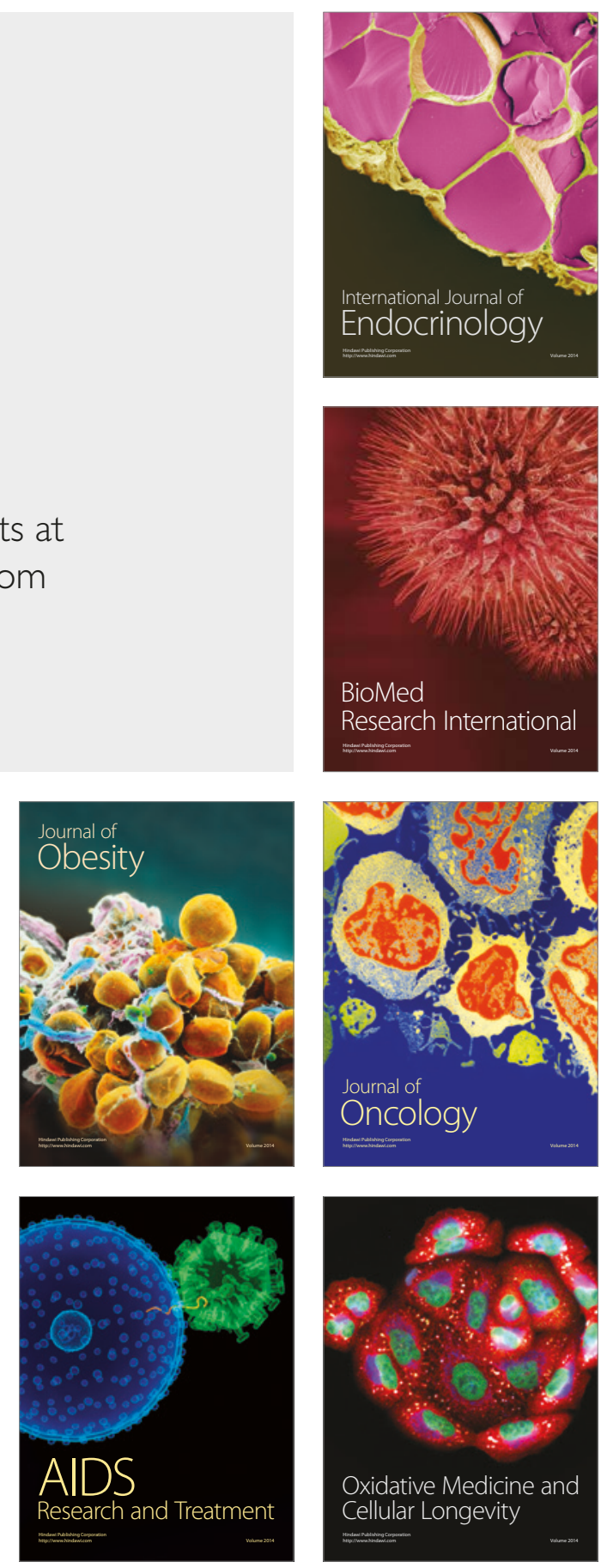